\title{
Effects of right ventricular morphology and function on outcomes of patients with degenerative mitral valve disease
}

\author{
Ying Ye, BS, ${ }^{a}$ Ravi Desai, MD, ${ }^{a}$ Lina M. Vargas Abello, MD, ${ }^{\mathrm{b}}$ Jeevanantham Rajeswaran, $\mathrm{PhD},{ }^{\mathrm{d}}$ \\ Allan L. Klein, MD, ${ }^{e}$ Eugene H. Blackstone, MD, ${ }^{\mathrm{c}, \mathrm{d}}$ and Gösta B. Pettersson, MD, $\mathrm{PhD}^{\mathrm{c}}$
}

Objective: The study objective was to investigate whether, in patients undergoing surgery for degenerative mitral valve disease, associated right ventricular remodeling and dysfunction are stronger determinants of preoperative organ dysfunction and prognosis than functional tricuspid regurgitation.

\begin{abstract}
Methods: From January 2001 to January 2011, 4197 patients underwent primary mitral valve surgery for degenerative valve disease at Cleveland Clinic. Using a quasi-experimental enriched study design, 781 patients were randomly selected within each grade of functional tricuspid regurgitation. Renal function was assessed by glomerular filtration rate and blood urea nitrogen, and hepatic function was assessed by Model for End-stage Liver Disease (MELD) score. Preoperative and postoperative right ventricular morphology and function were measured de novo on stored echocardiographic images. To assess survival, 3471 patient-years of follow-up data were available for analysis.
\end{abstract}

Results: Several preoperative right ventricular variables, but not functional tricuspid regurgitation grade $(P>.05)$, were associated with preoperative renal and hepatic dysfunction, but neither was associated with early mortality ( $<6$ months after surgery). However, worse preoperative right ventricular myocardial performance index $(P=.001)$, but not functional tricuspid regurgitation grade $(P>.2)$, was among the risk factors for later mortality. Postoperative unadjusted right ventricular function, but not functional tricuspid regurgitation grade $(P \geq .2)$, was associated with both early $(P=.04)$ and later $(P=.01)$ mortality, but in multivariable analysis appeared to be a surrogate for worse preoperative condition.

Conclusions: Together with patient comorbidities and operative factors, right ventricular morphology and function are associated more strongly with preoperative organ dysfunction and prognosis than is functional tricuspid regurgitation severity in patients undergoing surgery for degenerative mitral valve disease. Our previous study showed that tricuspid valve repair remains the most effective treatment to improve right ventricular function. (J Thorac Cardiovasc Surg 2014;148:2012-20)

Supplemental material is available online.

\footnotetext{
From the Cleveland Clinic Lerner College of Medicine, ${ }^{\mathrm{a}}$ Cleveland, Ohio; Departments of Vascular Surgery ${ }^{\mathrm{b}}$ and Thoracic and Cardiovascular Surgery, ${ }^{\mathrm{c}}$ Heart and Vascular Institute; Department of Quantitative Health Sciences, ${ }^{d}$ Research Institute; and Department of Cardiovascular Medicine, ${ }^{\mathrm{e}}$ Heart and Vascular Institute, Cleveland Clinic, Cleveland, Ohio.

This study was supported by the American Association for Thoracic Surgery Summer Intern Scholarship, August 2011 (Y.Y.); in part by the Kenneth Gee and Paula Shaw, PhD, Chair in Heart Research (E.H.B.); and the Peter and Elizabeth C. Tower and Family Endowed Chair in Cardiothoracic Research, James and Sharon Kennedy, the Slosburg Family Charitable Trust, Stephen and Saundra Spencer, and Martin Nielsen (G.B.P.). These individuals and funding organizations played no role in the collection of data or analysis and interpretation of the data, and had no right to approve or disapprove publication of the finished manuscript.

Disclosures: Authors have nothing to disclose with regard to commercial support.

Received for publication Sept 24, 2013; revisions received Feb 20, 2014; accepted for publication Feb 26, 2014; available ahead of print April 1, 2014.

Address for reprints: Gösta B. Pettersson, MD, PhD, Department of Thoracic and Cardiovascular Surgery, Cleveland Clinic, 9500 Euclid Ave/Desk J4-1, Cleveland, OH 44195 (E-mail: petterg@ccf.org).

$0022-5223 / \$ 36.00$

Copyright (c) 2014 by The American Association for Thoracic Surgery

http://dx.doi.org/10.1016/j.jtcvs.2014.02.082
}

This is the last of a 3-part series examining the hypothesis that left-sided events resulting in functional tricuspid regurgitation (TR) also lead to right ventricular (RV) dysfunction. If true, this has important implications for preoperative surveillance of patients with left-sided valve disease, timing of surgery, choice of procedure (more particularly, of whether or not to perform concomitant tricuspid valve [TV] repair), postoperative management, and surgical outcomes. All 3 studies are based on an enriched quasi-experimental study design.

Part 1 focused on understanding the importance of preoperative RV dysfunction and functional TR accompanying mitral valve disease. ${ }^{1}$ We found that increasing TR grade was associated with higher RV pressure, increased tethering distance, larger right atrial size, and worsening RV function measured by both tricuspid annular plane systolic excursion (TAPSE) and myocardial performance index (MPI), particularly in $3+/ 4+$ TR. We concluded that RV dysfunction is likely as important as TR because it offers an explanation for the negative prognostic importance of TR. ${ }^{2}$

Part 2 focused on follow-up measurements of RV function and TR after mitral valve surgery. ${ }^{3}$ We found 


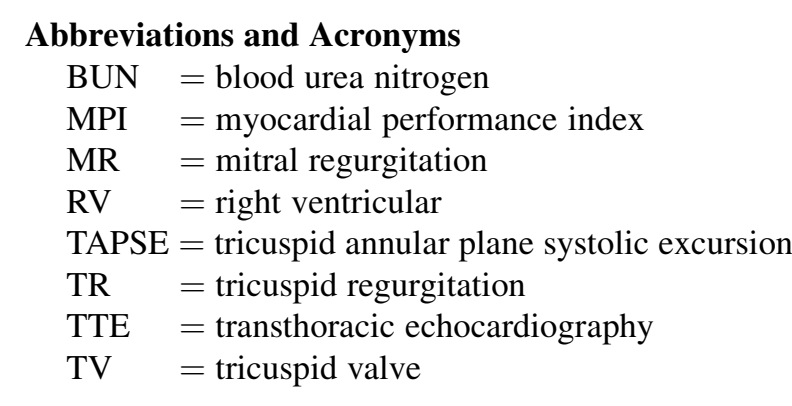

that patients with mild preoperative TR had reduced postoperative TR over the ensuing 3 years, but mild worsening of RV function. In patients with $3+/ 4+$ preoperative TR, mitral repair alone reduced postoperative TR and improved $\mathrm{RV}$ function; however, TR of $2+$ or greater returned postoperatively, and RV function worsened within 3 years, unlike in patients who had concomitant TV repair. We concluded that concomitant TV repair in patients with $3+/ 4+$ TR effectively and durably eliminated severe TR and was associated with an improvement of RV function toward normal, supporting an aggressive approach to important functional TR.

Part 3 focuses on clinical outcomes. We hypothesize that $\mathrm{RV}$ function and morphology may be more important prognostic markers than severity of TR for patients with functional TR undergoing mitral valve surgery. To test this hypothesis and understand the implications of RV function and morphology and TR for patient care and management, we investigated the association of preoperative RV morphology and dysfunction with organ dysfunction (renal and hepatic) and short- and long-term prognoses, and the effect of postoperative evolution of RV remodeling and TR on survival.

\section{METHODS}

From January 2001 to January 2011, 4197 patients underwent primary mitral valve repair or replacement, with or without TV repair, for degenerative valve disease at Cleveland Clinic. From the 3163 patients who met our inclusion and exclusion criteria of no structural TV disease, no intrinsic RV disease, and no evidence of coronary artery disease, ${ }^{1} 200$ were randomly selected from each preoperative TR grade $0+, 1+$, and $2+$ on transthoracic echocardiography (TTE); all 181 patients with grade $3+$ or $4+$ TR were included, totaling 781 patients (a quasi-experimental study design). Clinical grading of TR included evaluation of color TR jet area/right atrial area, vena contracta, proximal isovelocity surface area, and hepatic vein flow reversal. ${ }^{4-7}$ The study incorporated all patients in the 2 previous parts of this study, but doubled the study size to include more recent cases, thus increasing statistical power to detect associations with clinical outcomes. An important aspect of the study strategy was to include a full spectrum of TR grades, from no TR to severe.

This quasi-experimental study design accomplishes at least the following important things. First, it enriches the study with patients who potentially have RV dysfunction who may otherwise be lost in the overwhelming majority of patients with no TR and no RV dysfunction.
Second, it reduces by a factor of 5 the number of echocardiographic images that must be quantitatively assessed, permitting us to concentrate on the most important images. Third, it obviates any bias that may result from TR misclassification on clinical TTEs because of measurement error, intrinsic variability of functional TR, or interobserver variability. Finally, it neutralizes any effect of referral pattern. At increasingly higher grades of TR, average characteristics of patients-demographics, symptomatology, and renal and hepatic function-were progressively less favorable (Tables 1 and 2).

\section{Data Sources}

Organ dysfunction. Clinical data were extracted from the Cardiovascular Information Registry, a prospectively maintained registry, the clinical laboratory database, and the echocardiographic database. These and all other data used in this study were approved for use in research by the institutional review board, with patient consent waived.

Right heart morphology and function. De novo measurements were made offline from recorded echocardiograms for various right heart morphology and function variables before and after surgery, strictly following joint guidelines of the American Society of Echocardiography and European Association of Echocardiography. ${ }^{4}$ These included 4 measurements of right atrial morphology, 9 measurements of RV morphology, 8 measurements of RV function, and 3 measurements of valve dysfunction (Appendix E1). We used ProSolv Cardiovascular Analyzer 3.5 (ProSolv Cardiovascular, Indianapolis, Ind) and Syngo Dynamics 9.5 (Siemens Medical Solutions, Inc, Ann Arbor, Mich). Measurements were averaged over 3 cardiac cycles. It was possible to do this accurately in 137 of 139 patients in atrial fibrillation with no more variability than measurements from patients in sinus rhythm. All 781 patients had early postoperative TTEs. For patients followed at Cleveland Clinic, TTEs were obtained at approximately yearly intervals (Figure E1). Three observers (Y.Y., R.D., L.M.V.A.) collected echocardiographic data; interobserver and intraobserver variability for key variables are described in Appendix E1.

Survival. Survival data were obtained primarily by active follow-up at 2 and 5 years after surgery. These data were supplemented by interrogation of the Social Security Administration Death Master File for vital status, with a closing date of January 23, 2011. ${ }^{8,9}$ Median follow-up was 4.0 years (mean, $4.4 \pm 3.0$ years). Among surviving patients, $25 \%$ were followed more than 7 years and $10 \%$ were followed more than 9 years. A total of 3471 patient-years of data were available for analysis.

\section{Data Analysis}

Risk factors for preoperative organ dysfunction. Multivariable linear regression was used to identify preoperative factors (in particular measures of RV function, right heart morphology, and TR) associated with preoperative renal dysfunction, indicated by estimated glomerular filtration rate and blood urea nitrogen (BUN), and with preoperative liver dysfunction, indicated by the Model for End-stage Liver Disease (MELD) score. ${ }^{10}$ Variables considered in this analysis are listed in Appendix E2, and bagging was used for variable selection. ${ }^{11,12}$ This process involved random resampling and automated stepwise selection using variables listed in Appendix E2 (entry criterion $P<.10$, retention criterion $P<.05$ ). All variables with bootstrap reliability of $50 \%$ or greater were retained in the final model.

Postoperative evolution of right ventricular function, right heart morphology, and tricuspid regurgitation. RV function, right heart morphology, and TR grade were analyzed longitudinally after surgery for pattern of change across time. Nonlinear mixedmodel analysis was used to resolve the number of time phases to form a temporal decomposition model and to estimate shaping parameters of each phase. ${ }^{12-14}$ Implementation of the temporal decomposition model was by a nonlinear mixed-effects regression model ${ }^{14}$ for continuous repeated measurements and a nonlinear mixed-effects ordinal logistic 
TABLE 1. Preoperative patient characteristics and surgical management according to tricuspid valve regurgitation grade

\begin{tabular}{|c|c|c|c|c|c|c|c|c|c|}
\hline \multirow[b]{3}{*}{ Variable } & \multicolumn{8}{|c|}{ Tricuspid valve regurgitation grade } & \multirow[b]{3}{*}{$\boldsymbol{P} \dagger$} \\
\hline & \multicolumn{2}{|c|}{$\mathbf{0}(\mathbf{n}=\mathbf{2 0 0})$} & \multicolumn{2}{|c|}{$1+(\mathbf{n}=\mathbf{2 0 0})$} & \multicolumn{2}{|c|}{$2+(\mathbf{n}=\mathbf{2 0 0})$} & \multicolumn{2}{|c|}{$3+/ 4+(n=181)$} & \\
\hline & $\mathbf{n}^{*}$ & $\begin{array}{l}\text { No. }(\%) \text { or } \\
\text { Mean } \pm \text { SD }\end{array}$ & $\mathbf{n}^{*}$ & $\begin{array}{l}\text { No. }(\%) \text { or } \\
\text { Mean } \pm \text { SD }\end{array}$ & $\mathbf{n}^{*}$ & $\begin{array}{l}\text { No. }(\%) \text { or } \\
\text { Mean } \pm \text { SD }\end{array}$ & $\mathbf{n}^{*}$ & $\begin{array}{l}\text { No. }(\%) \text { or } \\
\text { Mean } \pm \text { SD }\end{array}$ & \\
\hline \multicolumn{10}{|l|}{ Demographics } \\
\hline Age (y) & 200 & $54 \pm 11$ & 200 & $59 \pm 11$ & 200 & $64 \pm 12$ & 181 & $70 \pm 11$ & $<.0001$ \\
\hline Female & 200 & $56(28)$ & 200 & $77(39)$ & 200 & $82(41)$ & 181 & $103(57)$ & $<.0001$ \\
\hline Body surface area $\left(\mathrm{m}^{2}\right)$ & 200 & $2.0 \pm 0.24$ & 200 & $2.0 \pm 0.25$ & 200 & $1.9 \pm 0.25$ & 181 & $1.9 \pm 0.26$ & $<.0001$ \\
\hline \multicolumn{10}{|l|}{ Cardiac morbidity } \\
\hline NYHA functional class & 194 & & 191 & & 189 & & 171 & & $<.0001$ \\
\hline I & & $87(45)$ & & $67(35)$ & & $71(38)$ & & $35(20)$ & \\
\hline II & & $86(44)$ & & $104(54)$ & & $86(46)$ & & $86(50)$ & \\
\hline III & & $21(11)$ & & $19(9.9)$ & & $29(15)$ & & $49(29)$ & \\
\hline IV & & $0(0)$ & & $1(0.52)$ & & $3(1.6)$ & & $1(0.58)$ & \\
\hline \multicolumn{10}{|l|}{ Noncardiac comorbidity } \\
\hline Bilirubin $\left(\mathrm{mg} \cdot \mathrm{dL}^{-1}\right)$ & 200 & $0.70 \pm 0.46$ & 197 & $0.75 \pm 0.48$ & 199 & $0.82 \pm 0.43$ & 177 & $0.86 \pm 0.47$ & $<.0001$ \\
\hline $\mathrm{BUN}\left(\mathrm{mg} \cdot \mathrm{dL}^{-1}\right)$ & 199 & $17 \pm 4.6$ & 200 & $18 \pm 5.2$ & 200 & $19 \pm 6.0$ & 181 & $23 \pm 11$ & $<.0001$ \\
\hline Creatinine $\left(\mathrm{mg} \cdot \mathrm{dL}^{-1}\right)$ & 200 & $0.94 \pm 0.18$ & 199 & $0.95 \pm 0.22$ & 199 & $0.98 \pm 0.23$ & 180 & $1.1 \pm 0.57$ & .2 \\
\hline Hematocrit $(\%)$ & 198 & $42 \pm 4.0$ & 199 & $41 \pm 5.1$ & 199 & $40 \pm 4.3$ & 178 & $39 \pm 5.0$ & $<.0001$ \\
\hline MELD score & 200 & $7.2 \pm 1.2$ & 200 & $7.5 \pm 1.7$ & 200 & $8.0 \pm 2.2$ & 181 & $8.8 \pm 2.6$ & $<.0001$ \\
\hline \multicolumn{10}{|l|}{ Surgery } \\
\hline Mitral valve surgery & 200 & & 200 & & 200 & & 181 & & $<.0001$ \\
\hline Repair & & $192(96)$ & & $189(94)$ & & $181(92)$ & & $146(81)$ & \\
\hline Replacement & & $8(4.6)$ & & $11(5.5)$ & & $19(9.5)$ & & 35 (19) & \\
\hline TV repair $\ddagger$ & 200 & $0(0)$ & 200 & $3(1.5)$ & 200 & $23(12)$ & 181 & $126(70)$ & $<.0001$ \\
\hline
\end{tabular}

BUN, Blood urea nitrogen; $M E L D$, Model for End-stage Liver Disease; $N Y H A$, New York Heart Association; $S D$, standard deviation; $T V$, tricuspid valve. *Patients with data available. $\dagger$ For categoric variables, Mantel-Haenszel test of linear trend with increasing TV regurgitation grade; for continuous variables, equivalent test of Pearson correlation coefficient. ‡One patient had TV replacement.

regression model for ordinal repeated measurements (SAS PROC NLMIXED; SAS Institute Inc, Cary, NC).

Preoperative risk factors for death. Survival was assessed nonparametrically by the Kaplan-Meier method and parametrically by a multiphase hazard model. ${ }^{12}$ Reliable risk factors were identified by bagging using variables listed in Appendix E2, as described previously. ${ }^{11,12}$

Postoperative risk factors for death. The association of the longitudinal patterns of postoperative TAPSE and TR with mortality was assessed by treating TAPSE and TR as time-varying covariables, with preoperative measurements as baseline measurements. ${ }^{14}$

Missing data. Sporadic missing values (Figure E2), under the assumption of being missing at random, were imputed through 5-fold multiple imputation ${ }^{15}$ using the Markov Chain Monte Carlo technique with PROC MI (version 9.1, SAS Institute Inc). Regression coefficients and their variance-covariance matrix were estimated by combining results from the 5 models using PROC MIANALYZE (SAS Institute Inc).

\section{Presentation}

Continuous variables are summarized by mean \pm standard deviation or by median, 15th, and 85th percentiles, consistent with \pm 1 standard deviation. Categoric data are summarized by frequencies and percentages. Uncertainty is expressed by $68 \%$ confidence limits equivalent to \pm 1 standard error. All analyses were performed using SAS statistical software (version 9.1; SAS Institute Inc).

\section{RESULTS}

Risk Factors for Preoperative Organ Dysfunction

Renal dysfunction, manifested by lower preoperative estimated glomerular filtration rate, was associated with longer TV tethering distance, smaller TV fractional shortening, lower TAPSE, and larger left atrial volume, as well as older age, insulin-treated diabetes, and heart failure (Table 3). Renal dysfunction, manifested by higher preoperative BUN, was associated with higher RV systolic pressure, longer TV tethering distance, lower left ventricular ejection fraction, and larger end-diastolic right atrial area, as well as older age and other comorbidities (Table 3).

Liver dysfunction, manifested by higher MELD score, was associated with larger end-systolic right atrial area, smaller RV basal diameter, higher RV systolic pressure, larger end-systolic TV diameter, longer TV tethering distance, lower left ventricular ejection fraction, and larger end-systolic left atrial area, as well as heart failure (Table 3).

Neither renal nor liver dysfunction was associated with increasing degree of TR or quantitative measurements of $\mathrm{TR}$, including vena contracta and TR jet area $(P>.05)$.

\section{Postoperative Evolution of Right Ventricular Function and Tricuspid Regurgitation}

An in-depth analysis of the effect of mitral valve repair (with or without TV repair) on postoperative RV function has been published in Part 2 of this series, ${ }^{3}$ and the findings were the same in our expanded patient cohort. To summarize, after surgery, TAPSE initially declined but then rapidly improved over the next 6 months (Figure E3). MPI similarly worsened immediately after surgery and then improved 
TABLE 2. Left and right heart echocardiographic findings according to tricuspid valve regurgitation grade

\begin{tabular}{|c|c|c|c|c|c|c|c|c|c|}
\hline \multirow[b]{3}{*}{ Variable } & \multicolumn{8}{|c|}{ Tricuspid valve regurgitation grade } & \multirow[b]{3}{*}{$\boldsymbol{P} \dagger$} \\
\hline & \multicolumn{2}{|c|}{$\mathbf{0}(\mathbf{n}=\mathbf{2 0 0})$} & \multicolumn{2}{|c|}{$1+(n=200)$} & \multicolumn{2}{|c|}{$2+(\mathbf{n}=\mathbf{2 0 0})$} & \multicolumn{2}{|c|}{$3+/ 4+(n=181)$} & \\
\hline & n* & $\begin{array}{l}\text { No. }(\%) \text { or } \\
\text { Mean } \pm \text { SD }\end{array}$ & $\mathbf{n} *$ & $\begin{array}{l}\text { No. }(\%) \text { or } \\
\text { Mean } \pm \text { SD }\end{array}$ & $\mathbf{n}^{*}$ & $\begin{array}{l}\text { No. }(\%) \text { or } \\
\text { Mean } \pm \text { SD }\end{array}$ & n* & $\begin{array}{l}\text { No. }(\%) \text { or } \\
\text { Mean } \pm \text { SD }\end{array}$ & \\
\hline Mitral valve regurgitation grade & 200 & & 200 & & 200 & & 181 & & .2 \\
\hline $1+$ & & $1(0.5)$ & & $0(0)$ & & $0(0)$ & & $0(0)$ & \\
\hline $2+$ & & $0(0)$ & & $2(1)$ & & $2(1)$ & & $3(1.7)$ & \\
\hline $3+$ & & $23(12)$ & & $36(18)$ & & $21(11)$ & & $25(14)$ & \\
\hline $4+$ & & $176(88)$ & & $162(81)$ & & $177(89)$ & & $153(85)$ & \\
\hline LV mass index $\left(\mathrm{g} \cdot \mathrm{m}^{-2}\right)$ & 194 & $130 \pm 81$ & 195 & $130 \pm 31$ & 195 & $130 \pm 34$ & 172 & $130 \pm 88$ & .3 \\
\hline Left atrial diameter $(\mathrm{cm})$ & 187 & $4.6 \pm 0.69$ & 189 & $4.7 \pm 0.87$ & 192 & $4.9 \pm 0.84$ & 166 & $5.0 \pm 0.90$ & $<.0001$ \\
\hline LV end-diastolic volume (mL) & 195 & $150 \pm 45$ & 197 & $150 \pm 45$ & 195 & $150 \pm 45$ & 172 & $140 \pm 42$ & .0005 \\
\hline LV end-systolic volume (mL) & 195 & $49 \pm 24$ & 197 & $51 \pm 24$ & 194 & $47 \pm 24$ & 172 & $49 \pm 26$ & .4 \\
\hline LV ejection fraction $(\%)$ & 200 & $59 \pm 5.8$ & 199 & $59 \pm 6.9$ & 200 & $58 \pm 6.3$ & 180 & $57 \pm 8.4$ & .02 \\
\hline RV systolic pressure (mm Hg) & 200 & $23 \pm 12$ & 200 & $33 \pm 15$ & 200 & $44 \pm 19$ & 181 & $50 \pm 22$ & $<.0001$ \\
\hline Pulmonary valve regurgitation grade & 199 & & 198 & & 197 & & 179 & & $<.0001$ \\
\hline 0 & & $192(96)$ & & $107(54)$ & & $83(42)$ & & $67(37)$ & \\
\hline $1+$ & & $7(3.5)$ & & $86(43)$ & & $20(10)$ & & $19(11)$ & \\
\hline $2+$ & & $0(0)$ & & $5(2.5)$ & & $94(48)$ & & $13(7.3)$ & \\
\hline $3+$ & & $0(0)$ & & $0(0)$ & & $0(0)$ & & $65(36)$ & \\
\hline $4+$ & & $0(0)$ & & $0(0)$ & & $0(0)$ & & $15(8.4)$ & \\
\hline
\end{tabular}

$L V$, Left ventricular; $R V$, right ventricular; $S D$, standard deviation. *Patients with data available. $\dagger$ For categoric variables, Mantel-Haenszel test of linear trend with increasing TV regurgitation grade; for continuous variables, equivalent test of Pearson correlation coefficient.

over the first postoperative year (Figure E4). Postoperative TR was 0 or $1+$ in the majority of patients (Figure E5).

\section{Preoperative Risk Factors for Death}

Instantaneous risk of death varied across time and was decomposed into 2 components (Figure E6): an early peaking phase of risk occurring within 6 months of surgery and an accelerating phase of risk. Risk factors associated with deaths occurring in the early peaking phase included complete heart block or use of a pacer, mitral valve replacement instead of repair, and larger preoperative left ventricular end-systolic volume index (Table 4). Neither preoperative degree of TR measured qualitatively $(P>.2)$ or quantitatively nor RV remodeling or dysfunction $(P>.05)$ was associated with these early deaths. Death occurring 6 months or more after surgery was associated with higher preoperative MPI (Figure 1, A), and smaller left atrial diameter, as well as older age, smoking history, longer aortic clamp time, mitral valve replacement instead of repair, and higher preoperative BUN. Although preoperative renal dysfunction was associated with risk of later death (Figure 1,B), preoperative liver dysfunction was not $(P>.05)$.

\section{Postoperative Right Ventricular Function, Tricuspid Regurgitation, and Mortality}

The initial decline in RV function after mitral valve surgery as shown for TAPSE (Figure 2) coincided with the high early hazard phase of death. The subsequent rapid improvement in RV function coincided with the rapid decrease of hazard. Thus, there was an apparent parallel relation of the longitudinal pattern of postoperative RV function and early $(P=.04)$ and late $(P=.01)$ risk of death. However, after accounting for preoperative risk factors for mortality by multivariable analysis, this relationship was more likely to be a surrogate for these other preoperative factors (early hazard phase risk-adjusted $P=.2$; late hazard phase risk-adjusted $P=.08$ ). We found no relationship, either unadjusted $(P>.2)$ or after accounting for preoperative risk factors $(P>.4)$, between the temporal pattern of postoperative TR and mortality. The majority of patients with severe TR $(70 \%)$ underwent concomitant TV repair (Table 2).

\section{DISCUSSION}

\section{Study Design}

Attempts to understand how long-term prognosis is affected by functional TR have focused on patients already exhibiting RV failure ${ }^{16}$ or important TR, ${ }^{17}$ but we have found no study investigating how the evolution of RV morphology and function and TR affects survival. Our intention in Part 3 of our study was to fill this gap and determine the relationships between TR, right heart morphology, and RV function and outcomes. We used the same quasi-experimental approach as in Parts 1 and 2 of our study, ${ }^{1,3}$ expanding the population to increase statistical power, but still examining a pure population of patients with degenerative mitral valve disease and no, 
TABLE 3. Risk factors for preoperative organ dysfunction

\begin{tabular}{|c|c|c|c|}
\hline Risk factor & Coefficient \pm SE & $\boldsymbol{P}$ & $\begin{array}{l}\text { liability } \\
(\%)^{*}\end{array}$ \\
\hline \multicolumn{4}{|l|}{ Renal dysfunction } \\
\hline \multicolumn{4}{|l|}{ Lower eGFR } \\
\hline Longer TV tethering distance $\dagger$ & $1.3 \pm 0.63$ & .04 & 78 \\
\hline $\begin{array}{l}\text { Smaller TV fractional } \\
\text { shortening } \ddagger\end{array}$ & $-31 \pm 14$ & .03 & 61 \\
\hline Lower TAPSE $\S$ & $0.26 \pm 0.104$ & .01 & 67 \\
\hline Larger LA volume $\|$ & $2.1 \pm 0.82$ & .01 & 81 \\
\hline Older age & $-0.47 \pm 0.051$ & $<.0001$ & 100 \\
\hline Insulin-treated diabetes & $-23 \pm 7.5$ & .002 & 91 \\
\hline Heart failure & $-6.6 \pm 1.6$ & $<.0001$ & 94 \\
\hline \multicolumn{4}{|l|}{ Higher BUN } \\
\hline Higher RV systolic pressure & $0.0302 \pm 0.012$ & .01 & 78 \\
\hline $\begin{array}{l}\text { Longer TV tethering } \\
\text { distance } \Phi\end{array}$ & $1.4 \pm 0.50$ & .005 & 72 \\
\hline Lower LV ejection fraction\# & $5.7 \pm 1.4$ & $<.0001$ & 79 \\
\hline $\begin{array}{l}\text { Larger end-diastolic } \\
\text { RA area** }\end{array}$ & $0.40 \pm 0.10$ & $<.0001$ & 81 \\
\hline Older age $\dagger \dagger$ & $1.8 \pm 0.303$ & $<.0001$ & 99 \\
\hline $\begin{array}{l}\text { Chronic obstructive } \\
\text { pulmonary disease }\end{array}$ & $3.5 \pm 0.82$ & $<.0001$ & 87 \\
\hline Heart failure & $2.8 \pm 0.62$ & $<.0001$ & 99 \\
\hline Carotid disease & $3.3 \pm 1.2$ & .005 & 57 \\
\hline $\begin{array}{l}\text { No peripheral arterial } \\
\text { disease }\end{array}$ & $-3.1 \pm 1.4$ & .02 & 41 \\
\hline \multicolumn{4}{|l|}{ Liver dysfunction } \\
\hline \multicolumn{4}{|l|}{ Higher MELD score } \\
\hline Larger end-systolic RA area & $0.012 \pm 0.0013$ & $<.0001$ & 64 \\
\hline Smaller RV basal diameter & $-0.043 \pm 0.012$ & .004 & 58 \\
\hline Higher RV systolic pressure $+\ddagger$ & $0.017 \pm 0.00604$ & .004 & 88 \\
\hline $\begin{array}{l}\text { Larger end-systolic TV } \\
\quad \text { diameter } \S \S\end{array}$ & $0.061 \pm 0.031$ & .05 & 75 \\
\hline $\begin{array}{l}\text { Longer TV tethering } \\
\text { distance } \Phi\end{array}$ & $0.028 \pm 0.015$ & .05 & 68 \\
\hline Lower LV ejection fraction & $0.13 \pm 0.039$ & .0008 & 82 \\
\hline Larger end-systolic LA area \|\| & $0.027 \pm 0.0091$ & .004 & 89 \\
\hline Male & $0.089 \pm 0.014$ & $<.0001$ & 95 \\
\hline Never smoked & $0.031 \pm 0.014$ & .02 & 60 \\
\hline Heart failure & $0.094 \pm 0.018$ & $<.0001$ & 99 \\
\hline Insulin-treated diabetes & $0.22 \pm 0.086$ & .01 & 62 \\
\hline
\end{tabular}

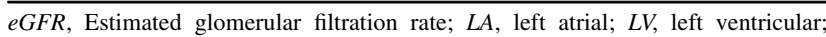
$M E L D$, Model for End-stage Liver Disease; $R A$, right atrial; $R V$, right ventricular; $S E$, standard error; TAPSE, tricuspid annular plane systolic excursion; $T V$, tricuspid valve; $B U N$, blood urea nitrogen. *Number of times factor appeared in 500 bootstrap models. $\dagger(1 / \mathrm{TV}$ tethering distance), inverse transformation. $\ddagger(\mathrm{TV}$ fractional shortening $)^{2}$, squared transformation. $\S \operatorname{Exp}(\mathrm{TAPSE})$, exponential transformation. $\|\left(60 /\right.$ LA volume), inverse transformation. $9(\mathrm{TV} \text { tethering distance })^{2}$, squared transformation. \#(50/LV ejection fraction), inverse transformation. **(RA area in diastole $/ 20)^{2}$, squared transformation. $\dagger \dagger \operatorname{Exp}($ age/50), exponential transformation.

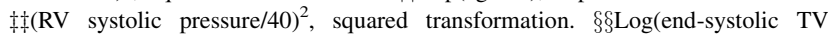
diameter), logarithmic transformation. \|\|$\left(\right.$ End-systolic LA area/30) ${ }^{2}$, squared transformation.

mild, moderate, or severe TR with no structural TV disease, intrinsic RV disease, or evidence of coronary artery disease. With this study design, exact TR grade is less important than obtaining a representative spectrum of $\mathrm{RV}$ function.
TABLE 4. Incremental risk factors for death

\begin{tabular}{|c|c|c|c|}
\hline Risk factor & Coefficient \pm SE & $\boldsymbol{P}$ & $\begin{array}{c}\text { Reliability } \\
(\%)^{*} \\
\end{array}$ \\
\hline \multicolumn{4}{|l|}{ Early } \\
\hline Complete heart block/pacer & $2.0 \pm 0.65$ & .002 & 46 \\
\hline Mitral valve replacement & $2.8 \pm 0.73$ & .0001 & 43 \\
\hline $\begin{array}{l}\text { Larger LV end-systolic } \\
\text { volume index } \dagger\end{array}$ & $0.32 \pm 0.12$ & .008 & 51 \\
\hline \multicolumn{4}{|l|}{ Late } \\
\hline Higher preoperative MPI $\ddagger$ & $1.2 \pm 0.37$ & .001 & 55 \\
\hline Smaller left atrial diameter & & & 55 \\
\hline $4.2-<4.7 \mathrm{~cm}$ vs $<4.2 \mathrm{~cm}$ & $-1.2 \pm 0.57$ & .04 & \\
\hline $4.7-<5.2 \mathrm{~cm}$ vs $<4.2 \mathrm{~cm}$ & $-1.1 \pm 0.47$ & .02 & \\
\hline$\geq 5.2 \mathrm{vs}<4.2 \mathrm{~cm}$ & $-1.5 \pm 0.502$ & .0003 & \\
\hline Older age $\S$ & $1.02 \pm 0.26$ & .0001 & 86 \\
\hline History of smoking & $1.1 \pm 0.36$ & .002 & 75 \\
\hline Longer aortic clamp time $\|$ & $0.77 \pm 0.28$ & .008 & 46 \\
\hline Mitral valve replacement & $0.83 \pm 0.38$ & .03 & 67 \\
\hline Higher preoperative BUN & $0.38 \pm 0.72$ & $<.0001$ & 88 \\
\hline
\end{tabular}

\section{Risk Factors for Preoperative Organ Dysfunction}

In accordance with previous studies, preoperative organ dysfunction correlated with patient characteristics and morphology and function of the left side of the heart. ${ }^{18,19}$ In addition, preoperative renal and liver dysfunction were associated with dilatation of the right heart and worse RV function, but not with TR. If one believes that functional TR is caused by pulmonary congestion, elevated pulmonary artery pressure, and RV dilatation and dysfunction, it makes sense that right heart morphology and function may be of more prognostic importance than TR and suggests that we pay more attention to right heart morphology and RV function when evaluating patients with degenerative mitral valve disease who have impaired kidney and liver function. The association of right heart remodeling and dysfunction with preoperative organ failure provides more insight into why patients with right heart failure caused by mitral regurgitation (MR) experience renal and hepatic dysfunction. ${ }^{20,21}$

\section{Preoperative Risk Factors for Death}

Overall survival after surgery was excellent, with early elevated hazard of death giving way to a later lower, but steadily increasing, hazard phase. This biphasic pattern also was seen in an earlier study of mitral valve repair for degenerative valve disease. ${ }^{22}$ In the previous study, the hazard for reoperation showed the same pattern, suggesting a possible connection between repair failure and survival, an association we did not examine in this study.

Risk factors for early death all point to known factors associated with disease severity. ${ }^{23-26}$ The fact that return 

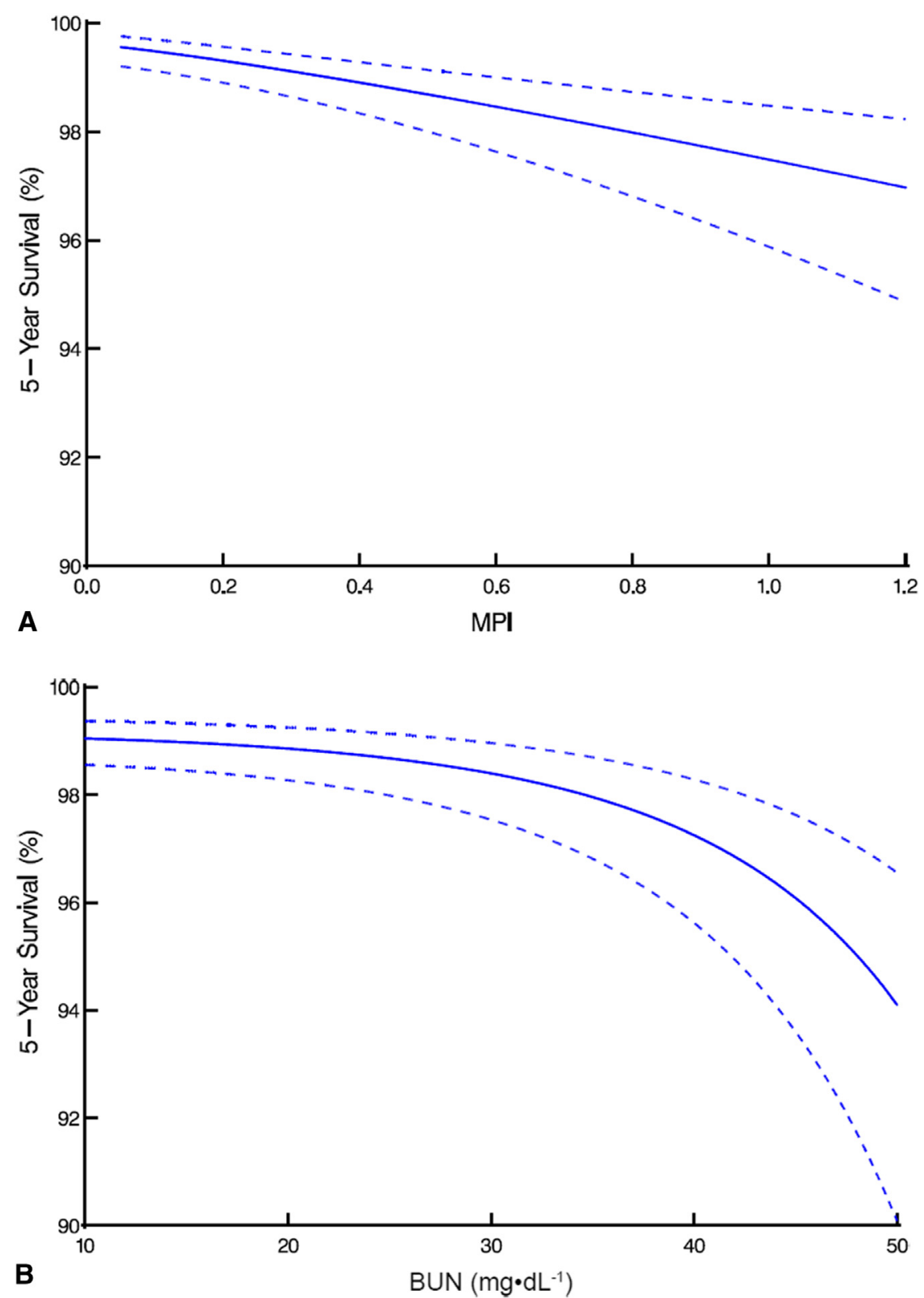

FIGURE 1. Relationship of preoperative risk factors to 5-year survival after mitral valve surgery with or without concomitant TV repair. A, Preoperative RV MPI. Solid line represents point estimates enclosed within a $68 \%$ confidence band for an individual with left ventricular end-systolic volume index $=25$ $\mathrm{mL} \cdot \mathrm{m}^{-2}$, no complete heart block/pacer, left atrial diameter $=4.2$ to $4.7 \mathrm{~cm}$, mitral valve repair, no history of smoking, $\mathrm{BUN}=20 \mathrm{mg} \cdot \mathrm{dL}{ }^{-1}$, and aortic clamp time $=72$ minutes. B, Preoperative BUN. Depiction is as in (A) except that MPI has been set at 0.42 . BUN, Blood urea nitrogen; MPI, myocardial performance index.

of MR and $\mathrm{TR}^{27,28}$ and changes in RV morphology ${ }^{1}$ occur later after mitral valve surgery explains why neither TR nor right heart morphology and function were risk factors for early death.

Risk of later death was associated with expected factors related to patient characteristics, including renal dysfunction, mitral valve replacement rather than repair, and the complexity of surgery as measured by aortic clamp time. ${ }^{18,26}$ Smaller left atrial diameter is unlikely to be a risk factor for later death, because other studies have more often linked left atrial dilatation to increased risk of cardiovascular events and death. ${ }^{29-31}$

Preoperative TR was not associated with increased mortality, neither early nor late. This is contrary to other studies that have demonstrated a relationship between residual and worsening TR and decreased survival. ${ }^{32}$ Severe preoperative functional TR has been associated with recurrent or residual TR after correction of the mitral 


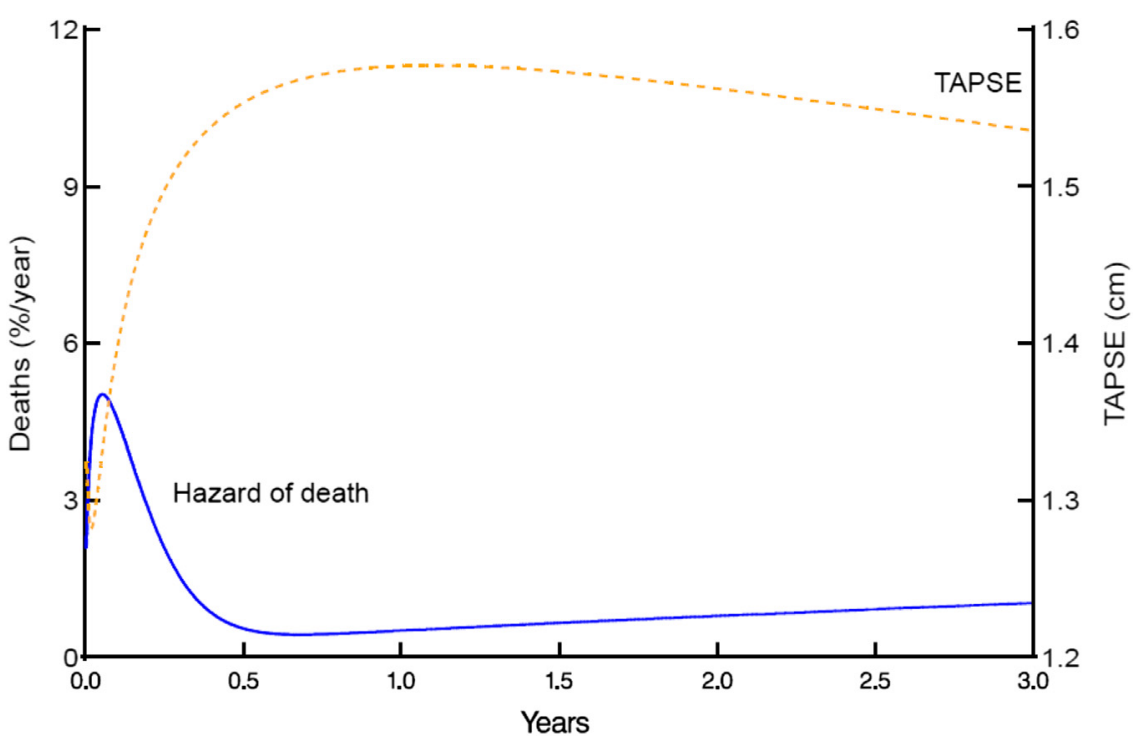

FIGURE 2. Instantaneous risk of death and postoperative TAPSE. Orange dashed line depicts the temporal trend of postoperative TAPSE. Blue solid line represents parametric estimate of risk of death. (Note expansion of early deaths compared with Figure E3, A.) TAPSE, Tricuspid annular plane systolic excursion.

valve pathology. ${ }^{33,34}$ However, these studies included a mixed patient population in whom mitral pathologies other than degenerative disease were present, whereas we focused purely on degenerative disease with severe MR being the indication for surgery and with each grade of functional TR represented in equal proportions.

In support of our hypothesis that RV dysfunction might be more important than TR, we found that worse preoperative RV function, specifically higher MPI, was associated with later death; however, this effect was small. Gallego-Delgado and colleagues ${ }^{35}$ also found preoperative TAPSE to be associated with worse prognosis in patients undergoing mitral valve surgery.

\section{Postoperative Right Ventricular Function, Tricuspid Regurgitation, and Mortality}

The postoperative longitudinal pattern of TR was not associated with survival, but the postoperative pattern of $\mathrm{RV}$ dysfunction was, before we adjusted for preoperative risk factors. In this and our previous study, we observed a decrease in TAPSE in the immediate postoperative period, followed by recovery toward normal within a few months. ${ }^{3}$ The effect does not last, but within 1 year after surgery, TAPSE slowly declines as hazard of death slowly increases. However, multivariable analysis revealed that postoperative changes in RV function and the risk of death appeared to be generally independent phenomena.

In contrast to the parallel, albeit largely independent, change in RV function with risk of death, we did not find even a univariable association between postoperative changes in TR and risk of death. We speculate that, driven by mitral valve disease, RV dysfunction and TR are both markers of advanced disease, and at the same time are both part of a self-perpetuating vicious cycle. Irrespective of causality, treating TR remains the best option to break the cycle, as demonstrated in Part 2 of this series. ${ }^{3}$ The majority of patients with severe TR underwent concomitant TV repair in our expanded cohort as well.

In patients with degenerative mitral valve disease and severe functional TR, concomitant TV repair effectively eliminated TR and was associated with improved RV function, in most cases nearing normal, and the effect was durable. After mitral valve repair alone, RV dysfunction and TR initially improved, but returned to preoperative levels within 3 years. A slow return of RV dysfunction also was seen in our expanded cohort. An aggressive and more liberal approach to TV repair in these patients is more likely to secure better long-term RV function.

\section{Study Strengths and Limitations}

Because this is a retrospective, albeit quasi-experimentally designed study, values for some preoperative and postoperative variables are incomplete. All patients underwent preoperative and immediate postoperative echocardiography. Over time, however, the number of patients returning for routine follow-up echocardiograms decreased. Most of the right heart variables were available from preoperative echocardiograms because of our standard protocol of evaluating patients before surgery. Postoperative echocardiograms had more missing data for right heart variables because a full echocardiogram is not routinely ordered. More follow-up echocardiograms were available for local patients.

Severity of TR used for selecting and categorizing patients was based on routine qualitative measurements 
made using standard American Society of Echocardiography echocardiographic grading criteria. ${ }^{4}$ We accepted the TR interpretations used for clinical decision-making; however, interobserver and intraobserver variability among clinical sonographers were not assessed, and we recognize that there is also intrinsic variability of functional TR. Our quasi-experimental study design makes it robust against TR misclassification as long as there is a positive correlation between TR and RV dysfunction, as demonstrated in Part 1 of this series. ${ }^{1}$ It is also robust against referral bias.

Only clinical, not research-quality, echocardiograms were available for measuring RV morphology and function, and differences in echocardiographic quality and viewing modalities could have affected the data. Further, several readers participated in obtaining de novo right heart echocardiographic measures. Interobserver and intraobserver variability were assessed for these variables, and the variations should have introduced little bias into our study (Appendix E1, including associated Appendix Figures E1-E4 and Appendix Tables E1 and E2).

It is also possible that our measurements may have been affected by the load dependence of TAPSE and MPI. ${ }^{36,37}$ Particularly in patients with severe TR, these echocardiographic measures may not solely reflect intrinsic RV function. Further, in patients with atrial fibrillation, these measurements are somewhat more difficult to obtain, and more data are missing.

Because of the small number of deaths that occurred in our patient population, the effects of TR, RV morphology and function, and other factors may not have been detected. For example, studying self-reported functional health status or quality of life may have disclosed stronger relationships with RV dysfunction and TR. ${ }^{35}$ Outcomes included the effect of TV repair according to current policy.

\section{CONCLUSIONS}

$\mathrm{RV}$ remodeling and dysfunction, rather than degree of TR, help explain preoperative organ dysfunction and survival in patients undergoing surgery for degenerative mitral valve disease. Longitudinal trend of postoperative RV dysfunction more closely parallels risk of death than does pattern of TR. Given that RV morphology and function are important to the prognosis of patients undergoing surgery for degenerative mitral valve disease, clinicians should pay more attention to the state of the RV when determining management and prognosis. Part 2 of this series showed that TV repair remains the most effective treatment to improve and secure better RV function.

\section{References}

1. Vargas Abello LM, Klein AL, Marwick TH, Nowicki ER, Rajeswaran J, Puwanant S, et al. Understanding right ventricular dysfunction and functional tricuspid regurgitation accompanying mitral valve disease. J Thorac Cardiovasc Surg. 2013;145:1234-41.e5.
2. Nath J, Foster E, Heidenreich PA. Impact of tricuspid regurgitation on long-term survival. J Am Coll Cardiol. 2004:43:405-9.

3. Desai RR, Vargas Abello LM, Klein AL, Marwick TH, Krasuski RA, Ye Y, et al. Tricuspid regurgitation and right ventricular function after mitral valve surgery with or without concomitant tricuspid valve procedure. J Thorac Cardiovasc Surg. 2013;146:1126-32.

4. Rudski LG, Lai WW, Afilalo J, Hua L, Handschumacher MD, Chandrasekaran K, et al. Guidelines for the echocardiographic assessment of the right heart in adults: a report from the American Society of Echocardiography endorsed by the European Association of Echocardiography, a registered branch of the European Society of Cardiology, and the Canadian Society of Echocardiography. J Am Soc Echocardiogr. 2010;23:685-713.

5. Cooper JW, Nanda NC, Philpot EF, Fan P. Evaluation of valvular regurgitation by color Doppler. J Am Soc Echocardiogr. 1989;2:56-66.

6. Nagueh SF. Assessment of valvular regurgitation with Doppler echocardiography. Cardiol Clin. 1998;16:405-19. vii.

7. Zoghbi WA, Enriquez-Sarano M, Foster E, Grayburn PA, Kraft CD, Levine RA, et al. Recommendations for evaluation of the severity of native valvular regurgitation with two-dimensional and Doppler echocardiography. J Am Soc Echocardiogr. 2003;16:777-802.

8. Boyle CA, Decoufle P. National sources of vital status information: extent of coverage and possible selectivity in reporting. Am J Epidemiol. 1990;131: 160-8.

9. Newman TB, Brown AN. Use of commercial record linkage software and vital statistics to identify patient deaths. J Am Med Inform Assoc. 1997;4:233-7.

10. Kamath PS, Kim WR. The model for end-stage liver disease (MELD). Hepatology. 2007; 45:797-805.

11. Breiman L. Bagging predictors. Machine Learning. 1996;24:123-40.

12. Blackstone EH. Breaking down barriers: helpful breakthrough statistical methods you need to understand better. J Thorac Cardiovasc Surg. 2001;122: 430-9.

13. Diggle PJ, Heagerty PJ, Liang KY, Zeger SL. Analysis of Longitudinal Data. 2nd ed. New York: Oxford University Press; 2002.

14. Mason DP, Rajeswaran J, Murthy SC, McNeill AM, Budev MM, Mehta AC, et al Spirometry after transplantation: how much better are two lungs than one? Ann Thorac Surg. 2008;85:1193-201.

15. Rubin DB. Multiple Imputation for Non-response in Surveys. New York: Wiley 1987.

16. Kim HK, Kim YJ, Park JS, Kim KH, Kim KB, Ahn H, et al. Determinants of the severity of functional tricuspid regurgitation. Am J Cardiol. 2006;98:236-42.

17. Fukuda S, Gillinov AM, Song JM, Daimon M, Kongsaerepong V, Thomas JD et al. Echocardiographic insights into atrial and ventricular mechanisms of functional tricuspid regurgitation. Am Heart J. 2006;152:1208-14.

18. Mehta RH, Eagle KA, Coombs LP, Peterson ED, Edwards FH, Pagani FD, et al Influence of age on outcomes in patients undergoing mitral valve replacement. Ann Thorac Surg. 2002;74:1459-67.

19. Stinebaugh J, Lavie CJ, Milani RV, Cassidy MM, Figueroa JE. Doppler echocardiographic assessment of valvular heart disease in patients requiring hemodialysis for end-stage renal disease. South Med J. 1995;88:65-71.

20. Lazzeri C, Valente S, Tarquini R, Gensini GF. Cardiorenal syndrome caused by heart failure with preserved ejection fraction. Int J Nephrol. 2011;2011: 634903.

21. Maeder MT, Holst DP, Kaye DM. Tricuspid regurgitation contributes to renal dysfunction in patients with heart failure. J Card Fail. 2008;14:824-30.

22. Gillinov AM, Cosgrove DM, Blackstone EH, Diaz R, Arnold JH, Lytle BW, et al Durability of mitral valve repair for degenerative disease. J Thorac Cardiovasc Surg. 1998;116:734-43.

23. Anyanwu AC, Adams DH. Functional tricuspid regurgitation in mitral valve disease: epidemiology and prognostic implications. Semin Thorac Cardiovasc Surg. 2010;22:69-75

24. Enriquez-Sarano M, Schaff HV, Orszulak TA, Tajik AJ, Bailey KR, Frye RL. Valve repair improves the outcome of surgery for mitral regurgitation. A multivariate analysis. Circulation. 1995;91:1022-8.

25. Meyer MA, von Segesser LK, Hurni M, Stumpe F, Eisa K, Ruchat P. Long-term outcome after mitral valve repair: a risk factor analysis. Eur J Cardiothorac Surg. 2007:32:301-7.

26. Samad Z, Kaul P, Shaw LK, Glower DD, Velazquez EJ, Douglas PS, et al. Impact of early surgery on survival of patients with severe mitral regurgitation. Heart. 2011;97:221-4.

27. Matsunaga A, Duran CM. Progression of tricuspid regurgitation after repaired functional ischemic mitral regurgitation. Circulation. 2005;112:I453-7. 
28. Shimokawa T, Kasegawa H, Katayama Y, Matsuyama S, Manabe S, Tabata M, et al. Mechanisms of recurrent regurgitation after valve repair for prolapsed mitral valve disease. Ann Thorac Surg. 2011;91:1433-9.

29. Kizer JR, Bella JN, Palmieri V, Liu JE, Best LG, Lee ET, et al. Left atrial diameter as an independent predictor of first clinical cardiovascular events in middle-aged and elderly adults: the Strong Heart Study (SHS). Am Heart J. 2006;151:412-8.

30. Laukkanen JA, Kurl S, Eranen J, Huttunen M, Salonen JT. Left atrium size and the risk of cardiovascular death in middle-aged men. Arch Intern Med. 2005;165: 1788-93.

31. Yi JE, Chung WB, Cho JS, Park CS, Cho EJ, Jeon HK, et al. Left atrial eccentricity in chronic mitral regurgitation: relation to left atrial function. Eur Heart J Cardiovasc Imaging. 2013;14:110-7.

32. Kirali K, Omeroglu SN, Uzun K, Erentug V, Bozbuga N, Eren E, et al. Evolution of repaired and non-repaired tricuspid regurgitation in rheumatic mitral valve surgery without severe pulmonary hypertension. Asian Cardiovasc Thorac Ann. 2004;12:239-45.
33. Matsuyama K, Matsumoto M, Sugita T, Nishizawa J, Tokuda Y, Matsuo T. Predictors of residual tricuspid regurgitation after mitral valve surgery. Ann Thorac Surg. 2003;75:1826-8.

34. Navia JL, Brozzi NA, Klein AL, Ling LF, Kittayarak C, Nowicki ER, et al. Moderate tricuspid regurgitation with left-sided degenerative heart valve disease: to repair or not to repair? Ann Thorac Surg. 2012;93:59-69.

35. Gallego-Delgado M, Arribas-Jimenez A, Santos JG, Garcia AM, Gonzalez-Sanchez T, Nieto-Ballestero F, et al. Right ventricular dysfunction: prognosis value in trial valve surgery. J Am Coll Cardiol. 2012;59: E1995.

36. Haddad F, Hunt SA, Rosenthal DN, Murphy DJ. Right ventricular function in cardiovascular disease, part I: Anatomy, physiology, aging, and functional assessment of the right ventricle. Circulation. 2008;117: 1436-48.

37. Weyman AE. Principles and Practice of Echocardiography. 2nd ed. Philadelphia: Lippincott Williams \& Wilkins; 1994. 


\section{APPENDIX E1. INTEROBSERVER AND INTRAOBSERVER VARIABILITY}

Interobserver variability for measurements of TAPSE and MPI function was assessed by 5 observers using 17 randomly selected echocardiograms from the overall collection of echocardiograms used in this study. Observers were blinded to results from other observers. Intraobserver variability on all right heart morphology and function variables was assessed by 1 observer (Y.Y.) using 20 randomly selected echocardiograms from the overall collection of echocardiograms used in this study. Measurements were conducted 1 month apart.

Pearson correlation was used to quantify the variability between different observers for TAPSE and MPI, and reproducibility by the same observer for all RV morphology and function variables.
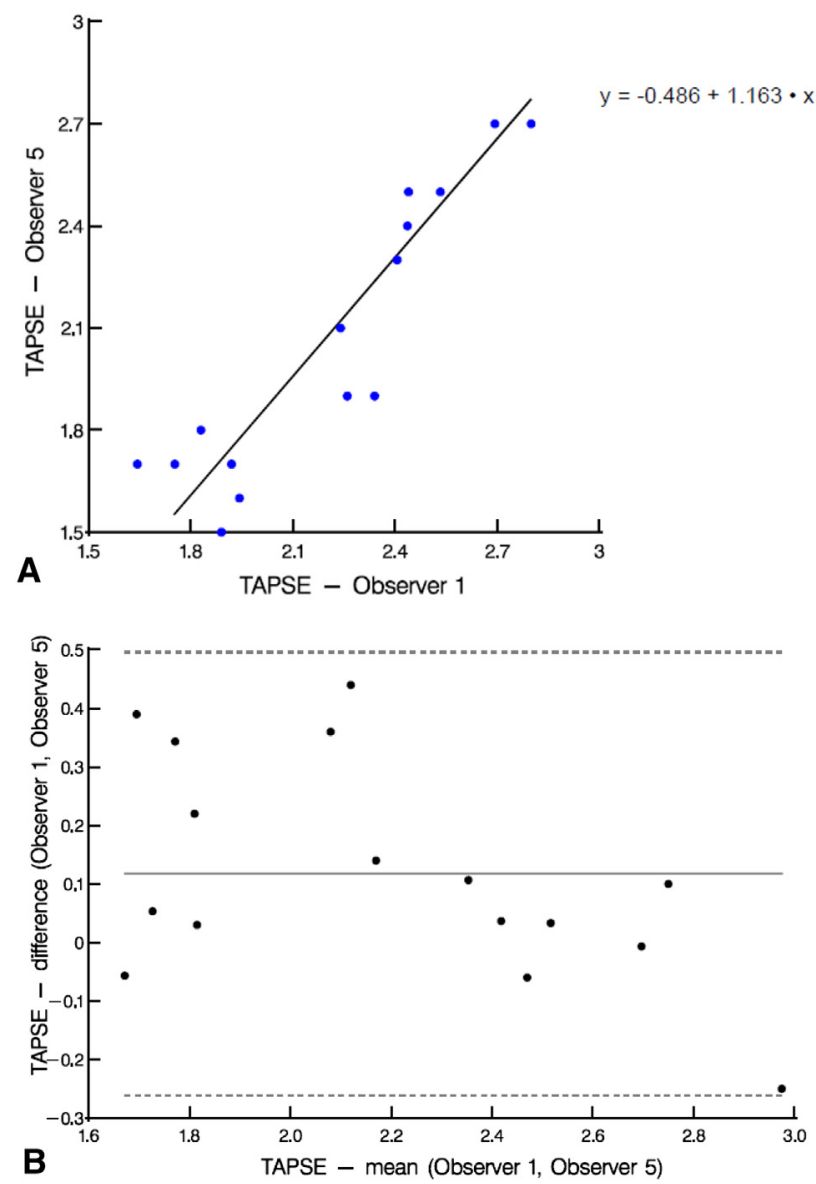

APPENDIX FIGURE E1. Interobserver correlation for TAPSE. A, Scatter plot. Black line represents linear trend of correlation between TAPSE measurements made by observers 1 and 5. B, Bland-Altman plot for TAPSE measurements made by observers 1 and 5. TAPSE, Tricuspid annular plane systolic excursion.
The least amount of variability existed between observers 1 and 5 (TAPSE, $r=0.93$; MPI, $r=0.80$; Appendix E1, Table E1, and Figures E1 and E2); the relationship of TAPSE and MPI measurements by observers 1 and 5 is plotted. More variability existed between observers 1 and 2 ; both contributed to measurement of RV morphology and function in this study.

Intraobserver variability for all $\mathrm{RV}$ morphology and function variables was analyzed for observer 1 (Appendix E1, Table E2, and Figures E3 and E4). Pearson correlations were greater than 0.9 for most variables, indicating good reproducibility of the obtained measurements. The most variability was in measuring tethering area $(r=0.64)$.
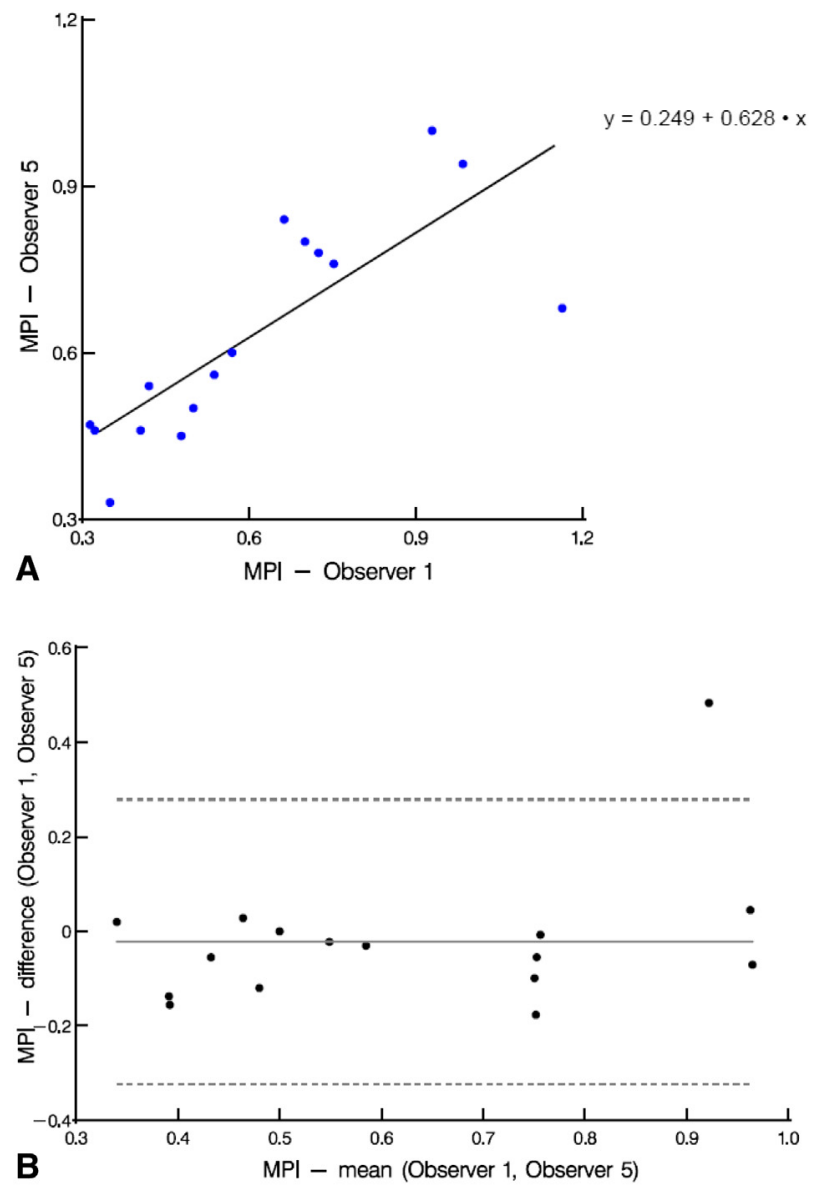

APPENDIX FIGURE E2. Interobserver correlation for MPI. A, Scatter plot. Black line represents linear trend of correlation between MPI measurements made by observers 1 and 5. B, Bland-Altman plot for MPI measurements made by observers 1 and 5. MPI, Myocardial performance index. 

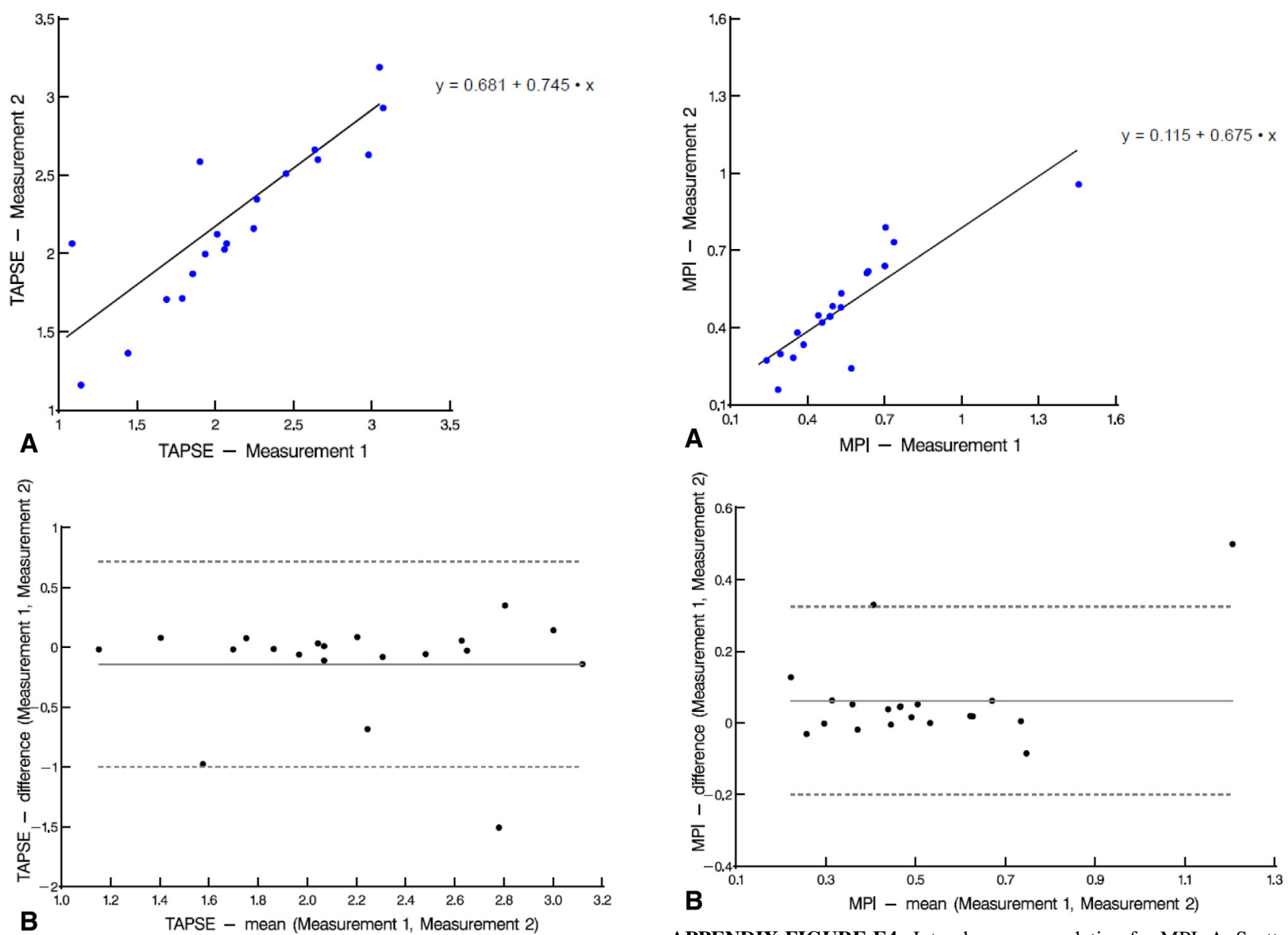

APPENDIX FIGURE E3. Intraobserver correlation for TAPSE. A, Scatter plot. Black line represents linear trend of correlation between TAPSE measurements made by observer 1 on 2 different occasions. B, Bland-Altman plot for TAPSE measurements made by observer 1 on 2 different occasions. TAPSE, Tricuspid annular plane systolic excursion.

APPENDIX FIGURE E4. Intraobserver correlation for MPI. A, Scatter plot. Black line represents linear trend of correlation between MPI measurements made by observer 1 on 2 different occasions. B, Bland-Altman plot for MPI measurements made by observer 1 on 2 different occasions. MPI, Myocardial performance index. 
APPENDIX TABLE E1. Interobserver variability: Pearson correlation coefficients between observers

\begin{tabular}{lcc}
\hline & MPI & TAPSE \\
\hline Observer 1 vs observer 2 & 0.32 & 0.59 \\
Observer 1 vs observer 3 & 0.40 & 0.76 \\
Observer 1 vs observer 4 & 0.33 & 0.72 \\
Observer 1 vs observer 5 & 0.80 & 0.93 \\
Observer 2 vs observer 3 & 0.41 & 0.33 \\
Observer 2 vs observer 4 & 0.59 & 0.36 \\
Observer 2 vs observer 5 & 0.18 & 0.56 \\
Observer 3 vs observer 4 & 0.32 & 0.86 \\
Observer 3 vs observer 5 & 0.72 & 0.64 \\
Observer 4 vs observer 5 & 0.15 & 0.68 \\
\hline
\end{tabular}

$M P I$, Myocardial performance index; TAPSE, tricuspid annular plane systolic excursion.
APPENDIX TABLE E2. Intraobserver variability: Pearson correlation for observer 1

\begin{tabular}{lc} 
& Pearson correlation \\
\hline Right atrial end-diastolic area & 0.98 \\
Right atrial end-systolic area & 0.97 \\
Right atrial minor dimension & 0.87 \\
Right atrial major dimension & 0.93 \\
RV basal diameter & 0.95 \\
RV base-apex length & 0.96 \\
RV end-diastolic area & 0.96 \\
RV end-systolic area & 0.94 \\
RV subcostal wall thickness & 0.92 \\
RV distal diameter & 0.99 \\
RV proximal diameter & 0.99 \\
TV end-diastolic annulus diameter & 0.96 \\
TV end-systolic annulus diameter & 0.94 \\
Tethering area & 0.64 \\
Tethering distance & 0.80 \\
TR jet area & 0.96 \\
Tricuspid regurgitation vena contracta & 0.94 \\
TAPSE & 0.73 \\
TV closing/opening time & 0.95 \\
Ejection time & 0.92 \\
MPI & 0.87 \\
\hline$M P I$, Myocardial performance index; $R V$, right ventricular; $T A P S E$, tricuspid annular \\
plane systolic excursion; $T R$, tricuspid regurgitation; $T V$, tricuspid valve.
\end{tabular}


APPENDIX E2. Right heart, left heart, patient characteristics, and procedural variables used in multivariable analyses

Right heart

Atrium:

Remodeling:

Ventricle:

Remodeling:

Function:

Valve dysfunction:

Patient

Demographic:

Symptoms:

Valve dysfunction:

Coronary anatomy:

Cardiac comorbidity:

Noncardiac comorbidity:

Experience:

Left heart

Atrium:

Left ventricle:

Structure:

Function:

Mass:

Support*

Procedure*
Right atrial area in systole $\left(\mathrm{cm}^{2}\right)$, area in diastole $\left(\mathrm{cm}^{2}\right)$, major dimension $(\mathrm{cm})$, minor dimension $(\mathrm{cm})$

RV base to apex length $(\mathrm{cm})$, TV tethering distance $(\mathrm{cm})$, TV tethering area $\left(\mathrm{cm}^{2}\right)$, proximal diameter $(\mathrm{cm})$, distal diameter $(\mathrm{cm})$, basal diameter $(\mathrm{cm})$, end-diastolic area $(\mathrm{cm})$, end-systolic area $(\mathrm{cm}), \mathrm{RV}$ area fractional shortening

Systolic pressure $(\mathrm{mm} \mathrm{Hg})$, TAPSE $(\mathrm{cm})$, MPI, TV diameter in systole $(\mathrm{cm})$, TV diameter in diastole $(\mathrm{cm})$, TV diameter shortening $(\mathrm{cm})$, TV fractional shortening, pulmonary valve resistance $\left(\right.$ dyne $\cdot \mathrm{cm} / \mathrm{s}^{2}$ )

Pulmonary regurgitation (grade 0-4+), TR (grade 0-4+), TR vena contracta

Age $(\mathrm{y})$, gender, weight $(\mathrm{kg})$, height $(\mathrm{cm})$, body surface area $\left(\mathrm{m}^{2}\right)$, body mass index $\left(\mathrm{kg} \cdot \mathrm{m}^{-2}\right)$

NYHA functional class (I-IV)

Mitral valve regurgitation, aortic valve regurgitation

Left main trunk disease ( $\%$ stenosis), left anterior descending coronary artery system disease (maximum \% stenosis), right coronary artery system disease (maximum $\%$ stenosis), left circumflex coronary artery system disease (maximum \% stenosis)

Atrial fibrillation, hypertension, history of cardiac disease, complete heart block/pacer, ventricular arrhythmia Treated diabetes, insulin-treated diabetes, history of peripheral arterial disease, history of smoking, carotid disease, popliteal disease, creatinine $\left(\mathrm{mg} \cdot \mathrm{dL}^{-1}\right), \mathrm{BUN}\left(\mathrm{mg} \cdot \mathrm{dL}^{-1}\right)$, bilirubin $\left(\mathrm{mg} \cdot \mathrm{dL}^{-1}\right)$, creatinine clearance, hematocrit $(\%)$, glomerular filtration rate, history of renal disease, history of stroke, Model for End-stage Liver Disease (MELD) score

Date of operation (years since January 1, 2001)

LA diameter $(\mathrm{cm})$, volume $(\mathrm{mL})$, volume index $\left(\mathrm{mL} \cdot \mathrm{m}^{-2}\right)$, systolic area $\left(\mathrm{cm}^{2}\right)$

Inner diameter in diastole $(\mathrm{cm})$, inner diameter in systole $(\mathrm{cm})$, diastolic volume $(\mathrm{mL})$, systolic volume $(\mathrm{mL})$, diastolic volume index $\left(\mathrm{mL} \cdot \mathrm{m}^{-2}\right)$, systolic volume index $\left(\mathrm{mL} \cdot \mathrm{m}^{-2}\right)$

Fractional shortening, ejection fraction (\%), relative wall thickness (wall stress)

Mass $(\mathrm{g})$, mass index $\left(\mathrm{g} \cdot \mathrm{m}^{-2}\right)$, posterior wall thickness $(\mathrm{cm})$, septal thickness $(\mathrm{cm})$

Aortic clamp time (min)

Mitral valve repair/replacement, TV repair/replacement

$\overline{B U N}$, Blood urea nitrogen; $L A$, left atrial; $M P I$, myocardial performance index; $N Y H A$, New York Heart Association; $R V$, right ventricular; TAPSE, tricuspid annular plane systolic excursion; $T R$, tricuspid regurgitation; $T V$, tricuspid valve. *Not considered in the multivariable analyses of preoperative organ dysfunction. 


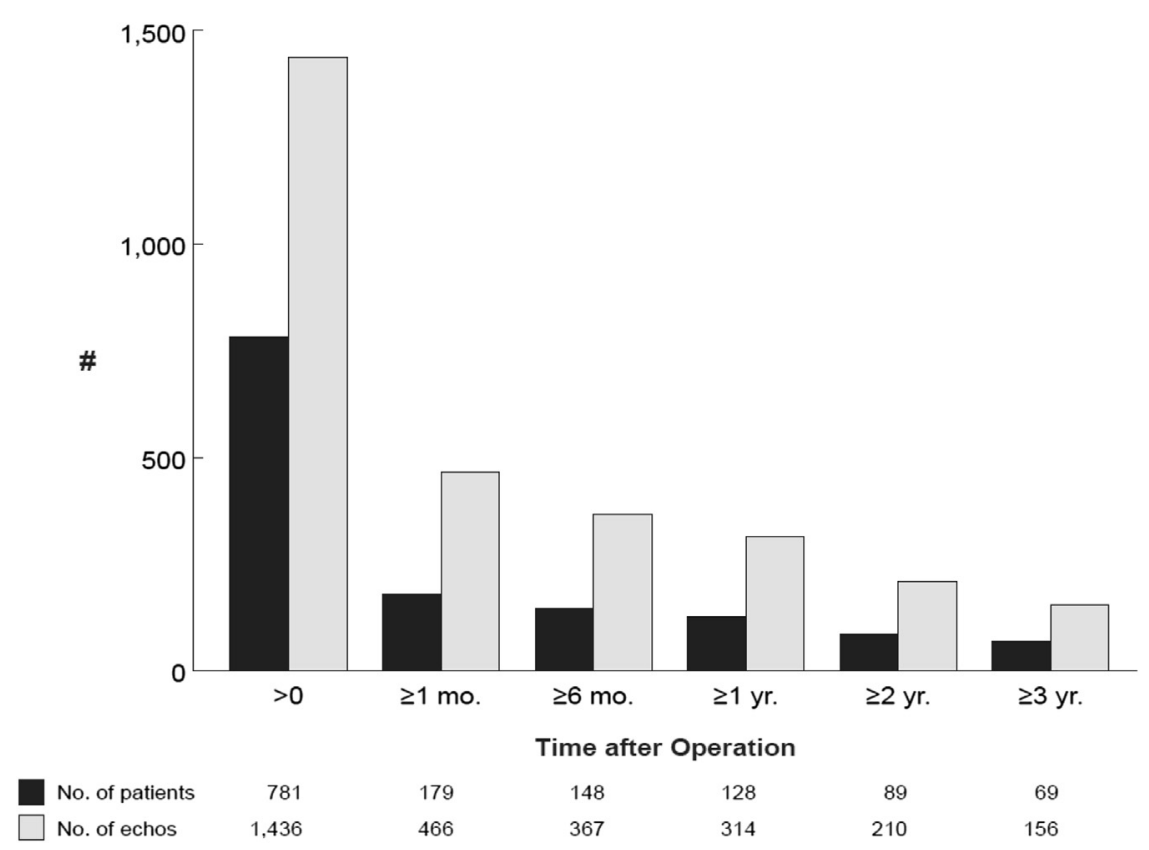

FIGURE E1. Number of patients with echocardiographic measurements available at and beyond various time points, and number of echocardiographic measurements available for analysis.

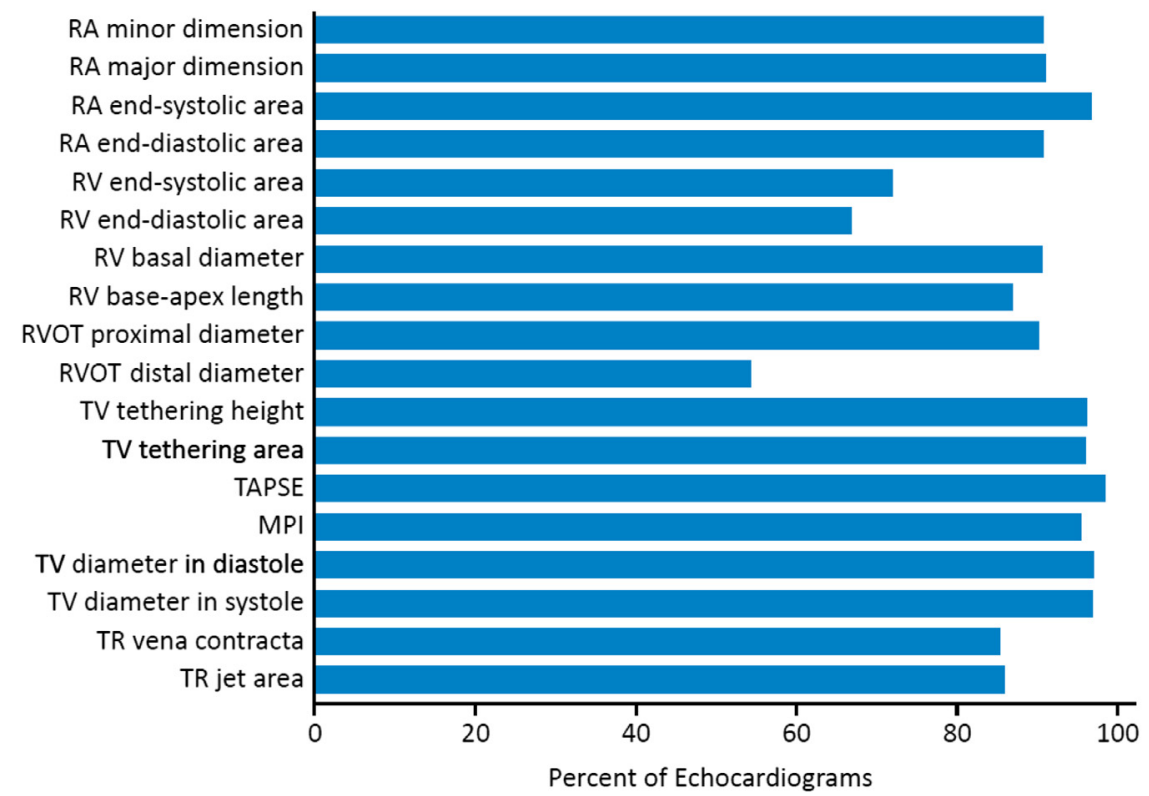

FIGURE E2. Percentage of preoperative echocardiograms (781 total) with nonmissing values for indicated variables. MPI, Myocardial performance index; $R A$, right atrial; $R V$, right ventricular; $R V O T$, right ventricular outflow tract; TAPSE, tricuspid annular plane systolic excursion; TR, tricuspid regurgitation; $T V$, tricuspid valve. 


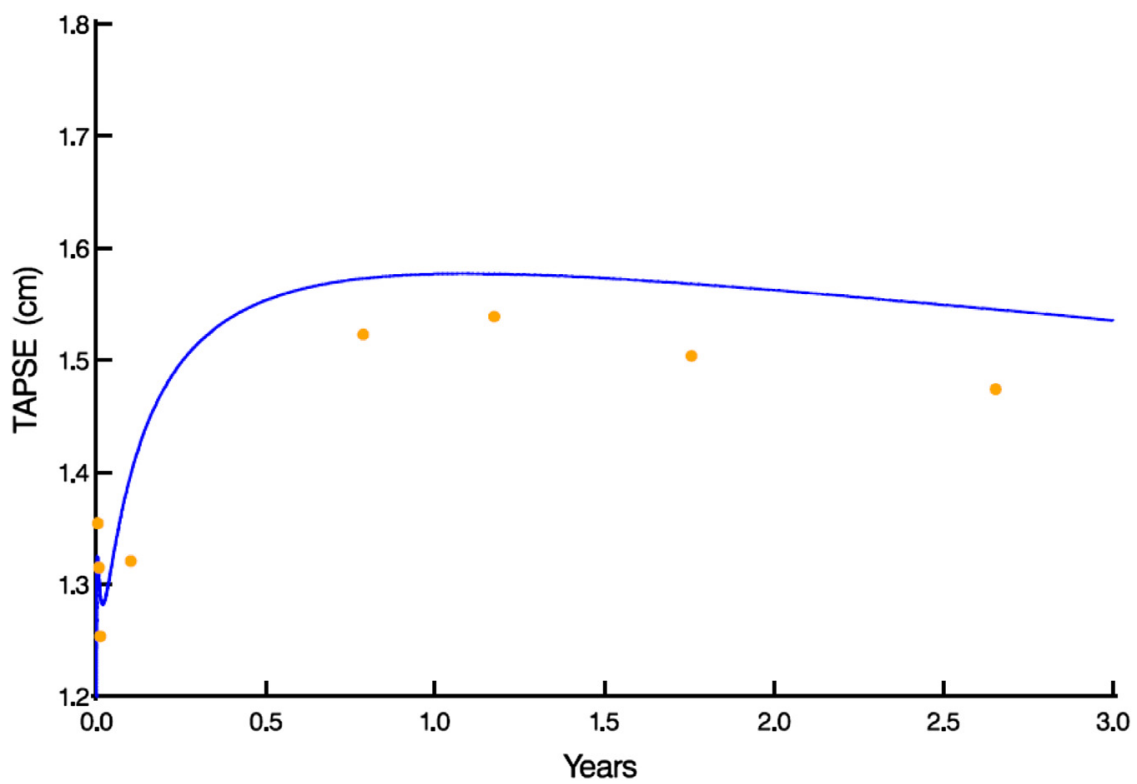

FIGURE E3. Mean TAPSE over time. Solid line represents unadjusted estimates of temporal trend of the mean response of postoperative TAPSE. Symbols represent data grouped (without regard to repeated measurements) within time frame to provide a crude verification of model fit. TAPSE, Tricuspid annular plane systolic excursion.

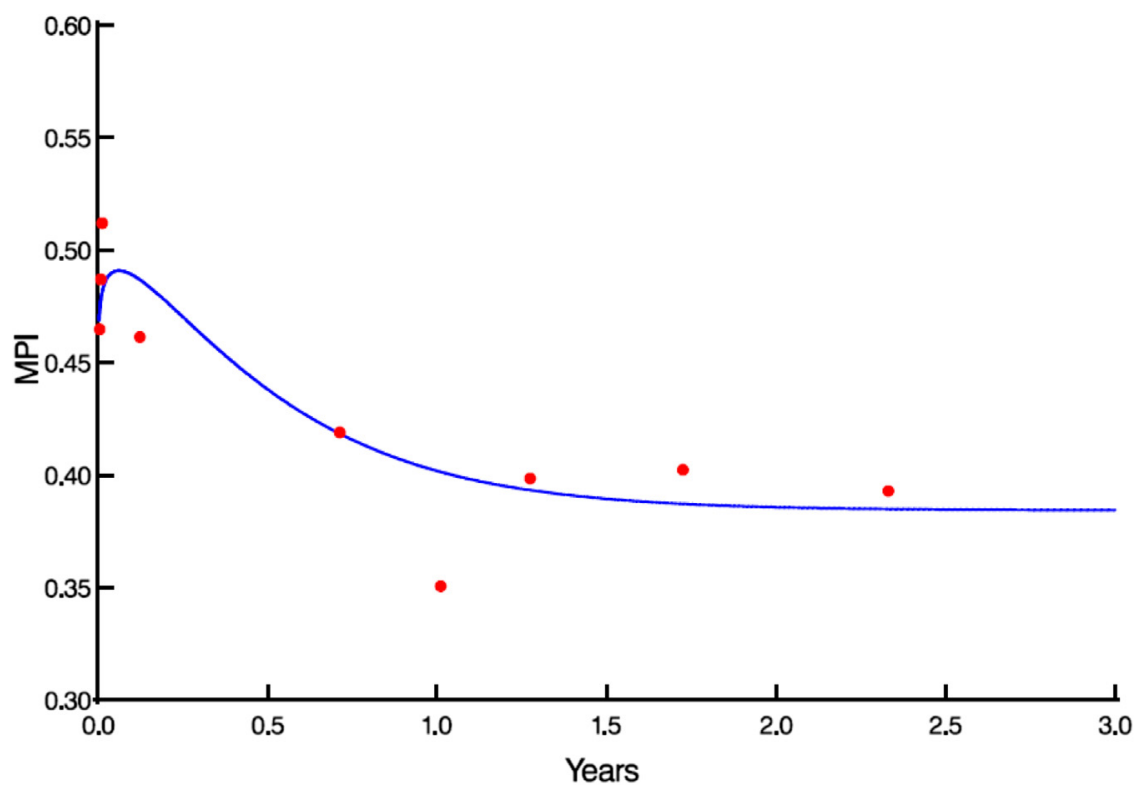

FIGURE E4. Mean MPI over time. Solid line represents unadjusted estimates of temporal trend of the mean response of postoperative MPI. Symbols represent data grouped (without regard to repeated measurements) within time frame to provide a crude verification of model fit. MPI, Myocardial performance index. 


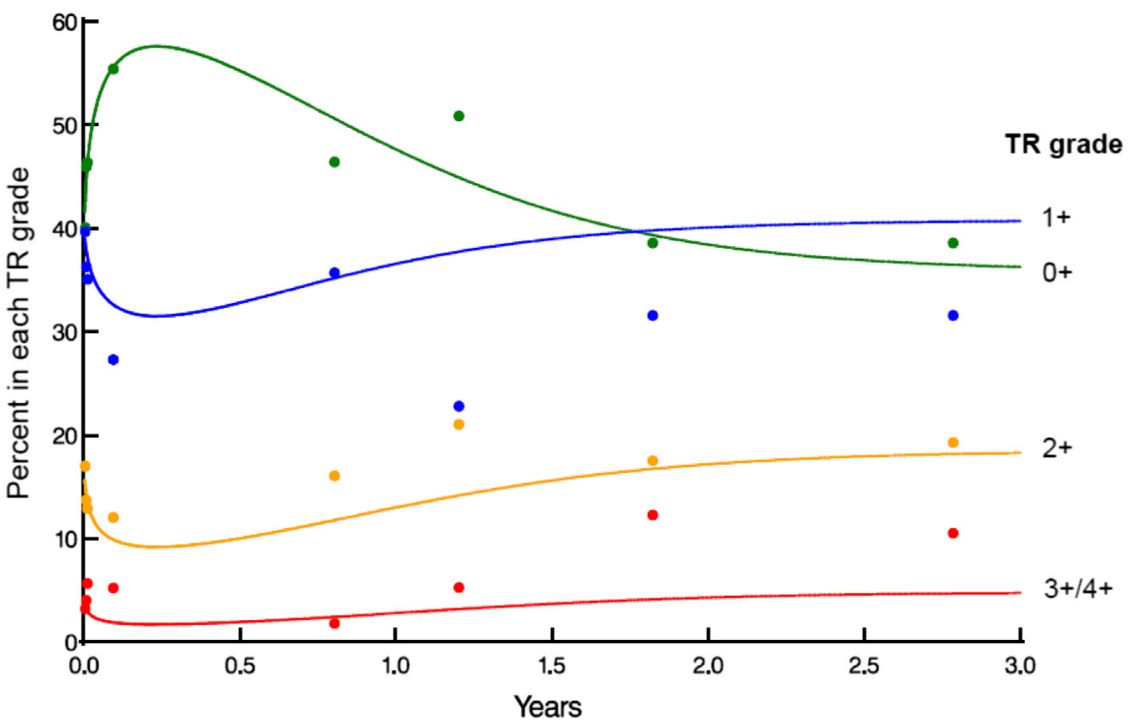

FIGURE E5. Prevalence of TR grades over time after mitral valve surgery with or without concomitant TV repair. Depiction is as in Figure E4. Solid line represents unadjusted estimates of temporal trend of the prevalence of postoperative TR grades. Symbols represent data grouped (without regard to repeated measurements) within time frame to provide a crude verification of model fit. $T R$, Tricuspid regurgitation. 

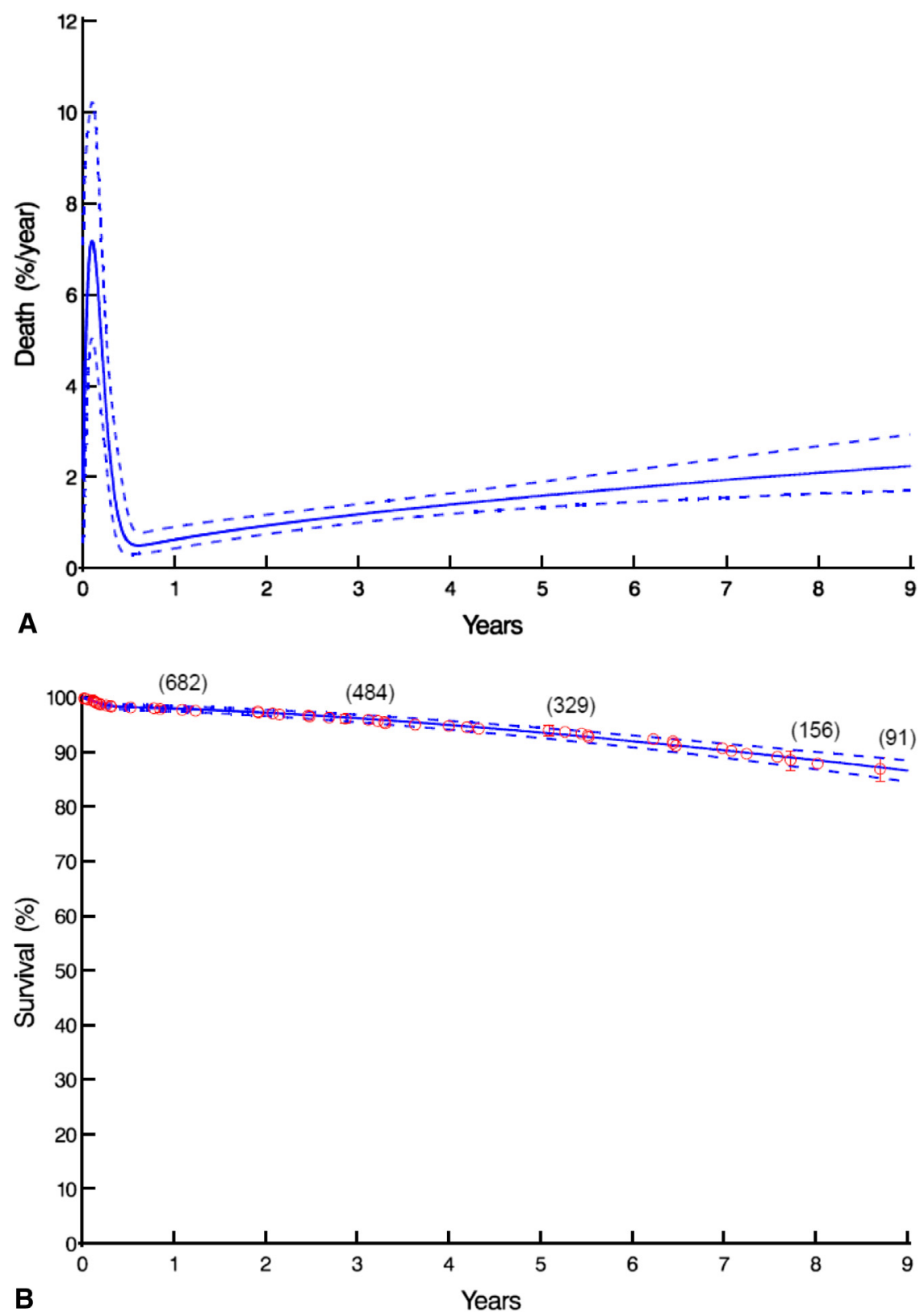

FIGURE E6. Death after mitral valve surgery. A, Instantaneous risk of death (hazard function) enclosed within a $68 \%$ confidence band equivalent to \pm 1 standard error. B, Survival. Each circle represents a death, vertical bars represent $68 \%$ confidence limits equivalent to \pm 1 standard error, and numbers in parentheses represent number of patients traced beyond that point. Solid line enclosed within a dashed $68 \%$ confidence band represents parametric survival estimates. 